\title{
Get the P.O.I.N.T. - Promoting Student Reflection and Teaching Effectiveness Using the Reflective Learning P.O.I.N.T
}

\author{
Ron Duggins \\ University of Central Arkansas
}

Herbert Simon, a Noble Prize economist said, "What information consumes is rather obvious. It consumes the attention of its recipients. Hence a wealth of information creates poverty of attention." Our students are flooded with more information and avenues of engagement with that information than ever before. The exercise discussed is the Reflective Learning P.O.I.N.T. and is meant to gain more of the students' attention, embed course content, and provide weekly feedback. This teaching case outlines the way this exercise is constructed and deployed and explores variations of the exercise as well as the benefits to both the student and instructor.

Keywords: Reflective Learning, Pedagogy, Engagement

\section{CASE BACKGROUND}

Herbert Simon, a Noble Prize economist said, "What information consumes is rather obvious. It consumes the attention of its recipients. Hence a wealth of information creates poverty of attention." This certainly seems to be the case today. Another issue today is the speed and scope of taking classes. Constraining the content of classes to semester (or shorter) long engagements and stacking this on top of multiple classes often contributes to academic amnesia or the inability and challenge of retaining information long term. These two issues are at the heart of this teaching case. How can instructors help students to allocate a bit more of their attention to the topics of the class and how can they make a deeper level connection with course content to gain longer term retention and action?

The Learning P.O.I.N.T. assignment is a student engagement strategy that can be used to gain some of the students' attention, but not in a social media fashion with just a few characters and a quick post. As instructors and facilitators see daily, one of the greatest barriers to communicating the content, skills, and messages is the noise in the lives of our students. Students are busy trying to rush through classes, often focused on a wide variety of subjects, to get the grade and move on toward graduation with little focus on knowledge retention and application. The Learning P.O.I.N.T. seeks to address this issues. While a deeper level of course/material engagement through reflection is the main objective of using the P.O.I.N.T. assignment there are other valuable benefits as well.

One of the additional benefits to an instructor is to provide a weekly assessment of the depth of engagement each student is having with the material. For more introverted students this assignment allows the instructor to gain insight into how the students are thinking and what they may be struggling with in the class. Another benefit of the P.O.I.N.T. is related to the respect shown to students. On a deeper 
level the P.O.I.N.T. assignment shows a respect for the knowledge and interest of the students by allowing them to explore and share their own thoughts and insights, instead of merely copying or regurgitating the course material.

A common goal among instructors is to help students become reflective learners and better problem solvers. Reflective learning is recognized as an important activity for immediate and long-term benefits of the formal educational process. Dahl, Peltier, and Schibrowsky (2018) provide an in-depth literature review of teaching critical thinking (reflection) in marketing education and acknowledge that the recognition of this need has been around for a very long time (Clabaugh, Forbes, \& Clabaugh, 1995; Hill \& McGinnis, 2007; Hopkins, Raymond, \& Carlson, 2011; Ronchetto \& Buckles, 1994). In response to the need for reflective learning activities in the class, instructors seek to develop new approaches to better fit the different circumstances and content of classes. Some of these activities include Reflective Journaling, "From the Other" writing assignments, and Failure Resumes. Another category are directed writings. The Learning P.O.I.N.T. explored here is similar to directed writings but based upon an inquiry model of questions.

The use of reflective learning exercises is one of the ways to operationalize the systems concept of double loop learning on an individual basis. Jaaron \& Backhouse (2016) relate three reasons that double loop learning is beneficial in organizations. The first is that double loop learning is a higher level of learning and more appropriate and effective in dynamic environments (Soltani et al., 2011). Secondly, the information gained through feedback (reflection) leads to confronting mental models and adjusting or iterating based upon the knowledge gained (Bagodi and Mahanty, 2013). Thirdly, the process of double loop learning strengthens the organization against competition by providing a basis for gaining new knowledge and acting on this to develop new competencies (Dahanayake and Gamlath, 2013).

In similar fashion to learning organizations, individuals and students, through their act of reflection, circle or loop back over the material to intentionally discover and make connections. Just as organizations can become more resilient and find success in the modern dynamic marketplace by developing double loop learning, students can also find deeper meaning and knowledge retention thereby becoming more successful. Due to the modern speed of education, students are not taking time to double back into the material to gain higher levels of learning or application. Orton (2014) writes that while we cannot force someone to be reflective, we can set up situations and conditions where true reflection will be more likely.

The following information outlines the use of the Reflective Learning P.O.I.N.T. that has proven effective in addressing the poverty of attention of students, the speed and scope of modern education that leads to academic amnesia, and the recognized importance of reflective learning.

\section{CASE BODY}

The Reflective Learning P.O.I.N.T. assignment asks students to focus some of their time and attention each week to reflect and write a Learning P.O.I.N.T. based around five questions focused on Perception, Observation, Impactful/Integration, New Information, and Tactics. In reflecting on my own learning and the hundreds of classes I have taken in higher education over the years I see within my own experience the need to have focused with intention more often in my coursework. Ask yourself or your colleagues about what they remember from specific classes and the likely answer will be, "I don't really remember many specifics." Of course, people will have a few highlights, but the opportunity to draw connections across content or to bring action to their learning are often missing in the rush to get through the material.

The Learning P.O.I.N.T. can be assigned as a private assignment between the student and instructor or written in a discussion board or openly shared format or platform. Each has advantages and drawbacks. When the P.O.I.N.T. is a private assignment the students may feel more comfortable sharing deeper or more personal topics. In my experience when these have been private assignments students share more often about failures and challenges in their lives and how these have shaped them. A drawback when

using this as a private assignment is that the other students miss the opportunity to learn from each other and engage in dialogue and discussion around their learnings. 
In using the P.O.I.N.T. in a discussion board or open format I have seen strong engagement, sharing, and discussion between students, especially at the graduate student level. But as mentioned, the open format may inhibit some students from sharing topics that they consider sensitive or even embarrassing.

It is my preference that the students engage the majority of the course material for the week before they have access to the P.O.I.N.T. assignment. In a learning management software (LMS) environment this means that the assignment won't open in the student's portal until the end of the week so that the students will have engaged both the reading material and sat through the majority of the class lectures/discussions. For Tuesday/Thursday classes the assignment opens at the end of class on Thursday and the students have until a specified time to submit the P.O.I.N.T. For a Monday/Wednesday/Friday class one could open the assignment also on a Thursday or wait until the Friday class has ended. Normally I set the due date/time on Friday at 11:59 p.m. of the same week, but depending on the class the due date/time can be over the weekend.

In regards to how much of the P.O.I.N.T. the students cover, the instructor has a great deal of flexibility. With five different focus points, this assignment can be fairly involved if an instructor wants the students to explore each area. My normal instructions to the students are to use the P.O.I.N.T. as a guide and not necessarily write something for each focus area each week, but rather select two or three that stand out for the week and write more thoughtfully and in-depth on these instead of just a few thoughts about all of the focus areas. There are normally a few students who write something for each area every time. For undergraduate students I have learned that the students need clear guidelines such as a minimum number of words and examples of both good and poor entries in order to benefit from the reflection.

An activity that enhances this assignment is to collate each student's entries at the end of the semester in a booklet or document that can be shared with the student. One way to introduce this work product is by telling students, "When you think back on this class and ask, 'What did I learn,' you will be able to draw upon this information and quickly know the value you gained. You will have at least 13 entries of reflected learning." These documents are also more likely and more easily retained, especially if provided in digital format. Considering that many students are renting books or selling their physical books these collated booklets become "packets of knowledge" to carry forward from the course.

This assignment in my courses is one of the highest weighted assignments in terms of the final grade as I want the student to understand the importance of reflection and begin to build this habit. There are also many ways to alter this assignment in order to fit various situations. To allow in-person peer to peer learning one may have the students break into pairs or triads and share their P.O.I.N.T responses with each other. Here are the suggested P.O.I.N.T.s:

P - PERCEPTION- What this week changed your PERCEPTION of (insert the course topic) and/or yourself and your thinking?

O - OBSERVE- What did you OBSERVE in real life that was a reflection of what you studied this week?

I - IMPACTFUL or INTEGRATE - What was the most IMPACTFUL content for you this week? How do you see the material integrating or tying into your other courses?

$\mathrm{N}$ - NEW - What was NEW for you this week? What mind shift may have occurred?

T - TACTIC - What TACTIC will you now pursue? What practical action will you take because of what you have learned?

PERCEPTION - What this week changed your PERCEPTION of (insert the course topic) and/or yourself and your thinking? The goal of asking about perception is to get the students to discuss how they view the material/content and world. It interesting to hear the students talk about having their perceptions changed because they were introduced to viewpoints they had not considered before or after they were exposed to new ideas and content.

OBSERVE - What did you OBSERVE in real life that was a reflection of what you studied this week? This question is meant to get the students looking beyond the confines of their current class and 
look for evidence and situations in the world where they see the implications of what they are learning in class. This is part of the "Just-In-Time" learning approach asking the students to pay attention to the wider world and what is happening today in terms of the course information.

IMPACTFUL or INTEGRATE - What was the most IMPACTFUL content for you this week? How do you see the material INTEGRATING or tying into your other courses? One may choose to use only one of these focus areas. When focusing on integration the students are challenged to activate the process of cross pollination of ideas and concepts by seeking connections with their broader coursework.

NEW - What was NEW for you this week? What mind shift may have occurred? This question focuses on what was new to simply to give the students the chance to talk about something that they had not known or considered before. Extending the question to the mind shift seeks to draw the student further down the reflection road to not just write a sentence about what was new, but to discuss the implications as well.

TACTIC - What TACTIC will you now pursue? What practical action will you take because of what you have learned? This question seek to start the students down the path of putting action to their learning. It is asking the students to engage the practical application and consequences of their learning and helps draw immediate connection to knowledge and behaviors.

\section{CONCLUSION}

In the ever challenging personal, cultural, and structural landscape of our students and education today, there is a need for more engaging and reflective activity with students. The Reflective Learning P.O.I.N.T. may be a tool you can use to implement and adapt in your own learning activities. There are many ways to iterate and change this approach to meet the specific needs of the course and students, but the focus on double loop learning increases the student's engagement as well as gives the professor a chance to continuously assess the learning of the students in the course. Future generations will only have more noise in their lives increasing the need for intentional reflection in education to help equip our students to be better learners and leaders. 


\section{REFERENCES}

Bagodi, V., \& Mahanty, B. (2013). Double loop learning in the Indian two-wheeler service sector. The Learning Organization, 20(4/5), 264-278.

Clabaugh, M. G., Forbes, J. L., \& Clabaugh, J. P. (1995). Bloom's cognitive domain theory: A basis for developing higher levels of critical thinking skills in reconstructing a professional selling course. Journal of Marketing Education, 17, 25-34.

Dahanayake, N.D., \& Gamlath, S. (2013) Learning organization dimensions of the Sri Lanka army. The Learning Organization, 20(3), 195-215.

Dahl, Peltier, \& Schibrowsky. (2018). Critical thinking and reflective learning in the marketing education literature: A historical perspective and future research needs. Journal of Marketing Education, 40(2), 101-116.

Hill, M. E., \& McGinnis, J. (2007). The curiosity in marketing thinking. Journal of Marketing Education, $29,52-62$.

Hopkins, C. D., Raymond, M. A., \& Carlson, L. (2011). Educating students to give them a sustainable competitive advantage. Journal of Marketing Education, 33, 337-347.

Jaaron, A., \& Backhouse, C. (2016). Operationalising "Double-Loop"' learning in service organisations: A systems approach for creating knowledge. Systemic Practice \& Action Research, 30(4), 317 337.

Orton, K. (2014). Reflective practice, what's the problem? Education Today, 64(3), 25-30.

Ronchetto, J. R., \& Buckles, T. A. (1994). Developing critical thinking and interpersonal skills in a services marketing course employing total quality management concepts and techniques. Journal of Marketing Education, 16, 20-31.

Soltani, E., Liao, Y., Wang, W. (2011) A learning organisation approach to managing service quality. In Proceedings of international joint conference on service sciences, Taipei, Taiwan. Retrieved December 12, 2015. 